\title{
HOMOGENEOUS BETA-TYPE FUNCTIONS
}

\section{MARTin Himmel AND JANUSZ MATKOWSKI}

Abstract. All beta-type functions, i.e. the functions $B_{f}:(0, \infty)^{2} \rightarrow(0, \infty)$ of the form

$$
B_{f}(x, y)=\frac{f(x) f(y)}{f(x+y)}
$$

for some $f:(0, \infty) \rightarrow(0, \infty)$, which are $p$-homogeneous, are determined. Applying this result, we show that a beta-type function is a homogeneous mean iff it is the harmonic one. A reformulation of a result due to Heuvers in terms of a Cauchy difference and the harmonic mean is given.

Mathematics subject classification (2010): 33B15, 26B25, 39B22.

Keywords and phrases: Beta function, Gamma function, beta-type function, pre-mean, mean, homogeneity, functional equation.

\section{REFERENCES}

[1] J. AczÉL, Lectures on Functional Equations and Their Applications, Academic Press, New York and London, 1966.

[2] J. AczéL, J. G. Dhombres, Functional Equations in Several Variables, Encyclopedia of Mathematics and its Applications, Cambridge University Press, 1989.

[3] H. AlzER, A harmonic mean inequality for the Gamma function, J. Comput. Appl. Math. 87 (1997), 195-198.

[4] K. J. Heuvers, Another logarithmic functional equation, Aeq. Math., 58 (1999), 260-264.

[5] Pl. Kannappan, Functional Equations and Inequalities with Applications, Springer Monographs in Mathematics, Springer, New York, 2009.

[6] M. KucZma, A. GILÁNYI, An Introduction to the Theory of Functional Equations and Inequalities, 2009, Birkhäuser Verlag AG, Basel - Boston - Berlin.

[7] M. Himmel, J. Matkows Ki, Directional convexity and characterizations of Beta and Gamma functions (submitted).

[8] J. MATKOWSKI, Convergence of iterates of pre-mean type mappings, ESAIM: Proceedings and Surveys, ECIT 2012, Witold Jarczyk, Daniele Fournier-Prunaret, João Manuel Gonçalves Cabral, November 2014, Vol. 46, 196-228. 